\title{
ПРАВОВОЙ ПЛЮРАЛИЗМ: ОТ ГЕНЕЗИСА ТЕОРЕТИЧЕСКОЙ КОНЦЕПЦИИ К РЕАЛИЗАЦИИ В СОВРЕМЕННЫХ УСЛОВИЯХ
}

Настоящая статья посвящена анализу понятия и содержания правового плюрализма, рассмотрению отдельных подходов (как отечественных, так и зарубежных авторов) к роли правового плюрализма и его значению для различных государств и правовых систем современности. Отмечается, что несмотря на многочисленные исследования в сфере правового плюрализма, в настоящее время отсутствует не только единый подход к определению данного института, но и единого мнения относительно наименования рассматриваемого явления.

В данном исследовании правовой плюрализм рассматривается не только с теоретико-правовых, но и историко-правовых позиций, что, несомненно, способно обогатить любой научный труд. В правовой доктрине исследуемая категория появилась сравнительно недавно, всего около 50 лет назад, что стало логичным результатом крушения колониальной системы и появления необходимости для новых независимых государств обеспечить сосуществование исторически сложившихся обычно-правовых норм с колониальным правом, распространённым метрополиями. Приводятся доводы относительно изменения понятия правового плюрализма с течением времени.
В статье раскрываются наиболее актуальные вопросы, касающиеся правового плюрализма, в частности, такие как особенности источников права в государствах с наличием правового плюрализма, исторические предпосылки к оформлению правового плюрализма и ряда других вопросов. Приводятся доводы относительно позитивного и негативного опыта правового плюрализма в различных странах мира. Рассматривается роль правового плюрализма в разрешении правовых конфликтов и реституционного правосудия. Делается вывод о необходимости дальнейшего исследования концепции правового плюрализма и изучения влияния данного института на правовые системы государств.

Научная новизна работы состоит в анализе зарубежной научной литературы, посвящённой правовому плюрализму, а также в выявлении положительных и отрицательных факторов правового плюрализма в современных условиях развития правовых систем различных государств.

Ключевые слова: правовой плюрализм, источники права, правовой обычай, колонии, нормативно-правовой акт, мусульманское право.

R. Gabrilyan, I. Klyukovskaya, E. Konina

\section{LEGAL PLURALISM: FROM THE GENESIS OF THEORETICAL CONCEPT TO IMPLEMENTATION IN MODERN CONDITIONS}

The presented paper covers the analysis of a study of the concept and the matter of "legal pluralism", an examination of approaches (both domestic and foreign authors) to the role of legal pluralism and its significance for various states and modern legal systems. It is noted that despite numerous studies in the field of legal pluralism, currently there is not a unified approach to the definition of this institution as well as a consensus on the name of the phenomenon under consideration.

In this study, legal pluralism is considered not only from the point of legal theory but also from the position of legal history, which, undoubtedly, can enrich any scholar paper. In the legal doctrine, the examined conception appeared relatively recently, only about 50 years ago. It was the logical result of the collapse of the colonial system and the emergence of the need for newly independent states to ensure the coexistence of historically established customary laws with colonial law distributed by metropoles. Arguments are given regarding the change in the concept of legal pluralism over time.
The article highlights the most topical issues concerning the legal pluralism, such as features of sources of law in states with the presence of legal pluralism, historical background to the evolution of legal pluralism and several other issues. Arguments are given regarding the positive and negative experience of legal pluralism in various countries of the world. The role of legal pluralism in resolving legal conflicts and restorative justice is also considered. The conclusion is drawn on the need to subsequent study the concept of legal pluralism and study the impact of this institution on the legal systems of states.

The scientific originality of the research lies in the analysis of foreign scientific literature on legal pluralism, as well as in the identification of positive and negative factors of legal pluralism in modern conditions of development of various states' legal systems.

Key words: legal pluralism, sources of law, custom, colonies, normative act, Muslim law. 
Вопросы, касающиеся сосуществования в рамках одной правовой системы нескольких элементов разных правовых систем, привлекают интерес учёных-правоведов на протяжении последних нескольких десятилетий. Однако несмотря на кажущуюся определённость, до сих пор не выработано ни общепринятого понятия правового плюрализма, ни единого подхода к его сущности, роли и значению. Более того, не имеется даже единообразного мнения по поводу наименования данного института. Так, рядом исследователей вообще не используется категория «правовой плюрализм», при этом выбор делается в пользу иных синонимов, таких как «юридический плюрализм», «децентрализм» или «полиюридизм».

Видный американский исследователь проблематики правового плюрализма Брайан 3. Таманаха говорит о том, что правовой плюрализм обнаруживается, буквально, везде, имея в виду множественность правовых порядков, начиная с местного и, заканчивая, глобальным уровнем. Автор указывает на сосуществование таких привычных правовых норм как сельские, городские, иные муниципальные с государственными, региональными, национальными, транснациональными и международными правовыми нормами. Однако в дополнение к указанным общепризнанным правовым нормам, в различных точках нашей планеты наличествуют более экзотические формы права, такие как обычное право, право коренных народов, религиозные нормы и нормы, связанные с различными этническими или культурными группами общества. Исследователь наблюдает очевидный рост квази-правовой деятельности, от частной охраны общественного порядка и правосудия (о чём писал также Н. Рулан [10, с. 281], до частных тюрем и постоянного развития обычного торгового права (lex mercatoria). Наконец, Таманаха выделяет правовые нормы транснационального коммерческого права, которые практически целиком являются продуктом частной законотворческой деятельности [20, р. 375].

Среди отечественных исследователей также выделяются примечательные мнения относительно природы правового плюрализма. Так, например, Антонов М. В. считает, что «правовой плюрализм в современной интерпретации сконцентрирован на противопоставлении права государства праву общества» [2, с. 157], сложно с данным высказыванием не согласиться, учитывая, что, оно ярко прослеживается в приведённом выше мнении Б. Таманахи.

Концепция правового плюрализма, естественно не является новой. Менее полувека назад данный термин впервые стал использоваться в научной юридической литературе. Данное явление имеет простое объяснение, именно в те годы, при столкновении двух идеологически противоположных лагерей, в результате непримиримой борьбы за освобождение от колониальной зависимости народов различных континентов и регионов Земли от Южной Америки до Океании, на политической карте мира появляется множество новых независимых государств.
Целый ряд из государств, обретших суверенитет, столкнулся с серьёзной дилеммой. На протяжении многих веков своей доколониальной истории, население большинства из новообразованных государств руководствовалось исторически сложившимися обычаями, передававшимися устно из поколения в поколение.

Европейские колонисты, захватывая всё новые и новые территории, стремились распространять на них и своё право. Естественно, в подавляющем большинстве случаев исторически сложившиеся обычно-правовые нормы вступали в противоречие с привносимым правом западноевропейских, а впоследствии и иных колониальных держав

В результате борьбы с правовыми обычаями местного населения, европейцы, не без кровопролития насаждали новые порядки. Часть из обычаев коренных народов исчезла, другую приспособили под право колонистов. В некоторых территориях колониальными империями велась борьба на полное уничтожение местных правовых обычаев. Так, например, во Французской Полинезии, несмотря на устремления местного населения, правовой обычай как источник права официально не признаётся, в то время, как во всех других государствах и территориях региона такое признание обычное право получило, в том числе в рамках Конституций и конституционных актов.

Однако вести речь о правовом плюрализме, имевшем место на заре своей истории и современном правовом плюрализме, следует с разных позиций. С распространением глобализационных процессов, развитием международного частного права, в особенности после крушения одного из двух лагерей антагонистов, обозначается начало новой волны правового плюрализма. И, если ранний правовой плюрализм был только связан со взаимоотношениями между колониальным правом и обычным правом завоёванных, то на современном этапе к данным отношениям прибавились и отношения международные, в частности, упомянутое ранеe lex mercatoria.

Примечательно, что несмотря на то, что само понятие правового плюрализма вошло в научный оборот относительно недавно, это отнюдь не означает отсутствие данного института в более ранние периоды развития человечества. Так, например, И. Л. Бабич, рассматривая правовые обычаи адыгов, отмечает, что признанное на государственном уровне «сосуществование (адатно-шариатного) судопроизводства и советской правовой системы адыгов сохранялось в течении XIX и в начале XX в., вплоть до 1925 г. Позднее была установлена единая советская правовая система, но адат и шариат использовались неофициально» [3, с. 116].

Более того, рассматривая идеи различных учёных начала XX в., можно обнаружить, что о правовом плюрализме говорили гораздо ранее общепринятых на данный момент дат. Так, некоторые исследователи относят к основоположникам правового плюрализма австрийского учёного 
О. Эрлиха. В частности, Б. Дюпре, пишет о том, что вклад австрийского учёного в развитие правового плюрализма является ключевым, что связано с разработкой им теории «живого права» возникшей в качестве реакции на идеологию исключительного государство-центристского права Рассматривая «живое право» преимущественно как независимое от государства, Эрлих предложил так называемую научную концепцию права, связанную с правилами поведения [14, р. 298]

Однако данная точка зрения не находит поддержки у всех современных правоведов. Исследуя учение знаменитого австрийца, Антонов М. В. отмечает, что утверждение о причастности первого к фрормированию такой категории как правовой плюрализм, представляется не совсем верным так как некоторые постулаты учения Эрлиха идут вразрез с рассматриваемым институтом. В частности, вопросы вызывает противопоставление государственного права праву общественному, чего невозможно обнаружить у О. Эрлиха [2, с. 180]

Понятие правового плюрализма претерпевает трансформацию вслед за меняющимися значением и ролью данного явления. Так, на первом этапе развития правового плюрализма, под данным явлением понимали «наличие в рамках одного конкретного общества нескольких правовых механизмов, по-разному действующих в одинаковых ситуациях) (Дж. Жиллсан и Ж. Вандерлинден) [23, р. 19]; «положение дел, для любого социального поля, в котором встречается поведение, соответствующее более чем одному правовому порядку» (Дж. Гриффитс) [15, р. 2]; «ситуация при которой две или более правовые системы сосуществуют в одном социальном поле» (С. Э. Мерри) [16, р.870]. В следующем периоде развития правовой плюрализм стали рассматривать несколько иначе. От предложенного А. И. Ковлером «такого положения вещей, при котором поведение соответствует более чем одному правопорядку» $[7$, с. 38] до «множества разнообразных коммуникативных процессов, которые следуют за социальными действиями в рамках бинарного кода «легальное/нелегальное»» Гюнтера Тойбнера [21, р. 1456]

Непросто что-либо противопоставить точке зрения А. Бьянки, согласно которой, правовой плюрализм представляет собой явление, куда более сложное, нежели это может показаться на первый взгляд. Под вывеской правового плюрализма скрывается целый ряд теорий. Правовой плюрализм можно понимать как сосуществование множества отдельных режимов в международном праве; трансформацию глобального общества в сложную структуру множества независимых систем с ограниченными формами взаимодействия друг с другом; единственную жизнеспособную альтернативу в мире, характеризующуюся множеством центров лояльности и притяжения в пост-национальных обществах; индивидуальный профессиональный вызов, психологический опыт, требующий твёрдого чувства персональной ответственности [13, р. 227-243].
Весьма аргументированное объяснение существующей неоднозначности трактовок правового плюрализма даёт $Ф$. фон Бенда-Бекманн, отмечающий, что много споров и недоразумений между правоведами-теоретиками и антропологами права, в том числе в отношении правового плюрализма, вызваны тенденцией приведения данных совершенно разных устремлений и вытекающих из этого концепций к одномерному уровню обсуждения, в котором авторы находятся в поиске одной единственно верной или утилитарной концепции как для правоведов, так и для социологов. При этом не принимается во внимание тот фракт, что данные группы учёных преследуют различные цели [24, р. 41].

В частности, автором приводится в качестве примера мнение знаменитого американского антрополога Л. Надер, критикующей «какофонию в правовых и антропологических исследованиях, касающихся права и общества» [17, р. 73].

При этом встречаются и светлые пятна, хотя и являются, скорее исключением. Так, представляется логичной точка зрения Зале, продемонстрировавшего осведомлённость в сущности данной проблемы [18, р. 197].

Данное, в особенности, заметно в теориях, в которых у многих учёных имеется запрос на универсальную оценку для своих концепций в абсолютном измерении. Фактически, они борятся за концептуальную гегемонию.

Ф. фон Бенда-Бекманн также заявляет, что указанный выше подход не только серьёзное препятствие на пути к качественно выстроенной юридической антропологии, он также делает диалог между представителями различных наук чрезвычайно сложным. Действительно, корни многих разногласий находятся в слишком ограниченном знании, когда, под влиянием стереотипов собственного учения, исследователям сложно принять концепции и подходы научных деятелей из смежных областей научного познания. Автором предлагается как представителям общей теории права, так и антропологам права работать над исследованиями, в которые вовлечены обе стороны. Таким образом, в то время как первыми будет ставится цель отстоять идеологию позитивного права, вторые не смогут стремиться в данных условиях к отношению к непризнанному праву как к праву государства. В случае, если одним приходится выбирать для правоприменения «правильные нормы», другим не получится применять достижения правового плюрализма в практической плоскости. Однако если одна сторона вовлечена в сравнительный анализ права через призму смены эпох и обществ, другая не будет воспринимать сравнительные процедуры как поглощенные доминирующей правовой идеологией.

Таким образом, прежде чем кому-либо вступить в концептуальные дебаты, ему следует чётко понимать, насколько различаются академические и профессиональные подходы, а также и их ограничения, а также принимать во внимание последствия продвижения своей точки зрения или критики других [24, p. 41-42]. 
К теории правового плюрализма зачастую обращаются в переходные периоды истории. Как справедливо отмечает Тихонова С. В. [11, с. 94], именно в такие времена ставится вопрос об одновременном существовании права государства и права социума, что, несомненно, привлекает учёных-правоведов.

Исследуя современное состояние правового плюрализма, нельзя не привести мнение М. В. Антонова, согласно которому, происходящие в настоящее время в мире глобализационные процессы, несомненно отражаются и на таком явлении как правовой плюрализм, однако данные процессы учёный предлагает рассматривать не просто для отражения современных реалий права, но, главным образом, в качестве регулирующей концепции для подтверждения признания определенных закономерностей эволюции общества со стороны учёных, юристов и политиков [12, р. 15]

Положительные черты правового плюрализма учёными нередко выводятся посредством противопоставления рассматриваемой концепции юридическому монизму. Действительно, если в качестве примера обратиться к странам Африки или Океании после получения ими независимости, одним из ключевых вопросов становится не только вопрос официального признания обычного права в качестве источника права, но и его преимущества перед позитивным правом, в особенности решения таких проблем как, например, коррупция. Несмотря на то, что обычное право располагает всем необходимым для решения подобных проблем, именно неписанное право выступает реальным инструментом для их искоренения.

Кроме того, говоря о таком явлении как коррупция, следует принимать во внимание не только западно-центристскую концепцию, но и учитывать особенности конкретного региона. Так, размышляя об указанном явлении в пост-советском Узбекистане, Р. Уринбоев и М. Свенссон говорят о необходимости иного подхода к данному явлению касательно узбекского народа, для которого под влиянием исторических, культурных и цивилизационных фракторов подобное, несомненно, негативное явление воспринимается несколько иначе нежели на Западе, где исторически сложилось крайне отрицательное отношение к коррупции, как к одному из серьёзных преступлений против государственной власти.

На основе исследования, проводившегося в Узбекистане данными учёными, авторы приходят к заключению, что международные институты, такие как Всемирный Банк, Транспаренси Интернейшнл занимают крайне западно-центристскую позицию, оценивая уровень и состояние коррупции в данной среднеазиатской стране. Так, некоторые неформальные действия, однозначно интерпретируемые международными институтами как «коррупция» не обязательно означает такого же отношения к ним самих местных жителей. Более того, проведённые наблюдения, изучение статистики и опросы населения продемонстри- ровали наличие существенно отличающихся от западных морали и норм поведения. Причём к схожим выводам пришли и три других группы антропологов права в 2000, 2005 и 2007 годах. Однако в упоминавшемся исследовании Р. Уринбоев и М. Свенссон находят решение проблемы в применении достижений правового плюрализма. Так называемые «неформальные действия», которые однозначно признаются в западном мире в качестве коррупционных преступлений, рассматриваются с позиций концепции «живого права». Применяя данную концепцию, исследователи задаются вопросом применимости западных норм (ставших основой для норм международного права, по крайней мере, в данной области). Неформальное право в данном случае выступает в роли паллиативного механизма, нивелирующего недостатки государственных механизмов, в частности, в сфере финансирования инфраструктуры и социального обеспечения граждан [22, р. 372 , 387-388]

Отметим, вышесказанное имеет непосредственное отношение не только к такому государству как Узбекистан, но и многим государствам в различных частях нашей планеты. Действительно, применение западных (будь то американских или европейских) подходов к оценке различных явлений правовой действительности в государствах и у народов с иной историей и культурой не представляется верным и именно правовой плюрализм в данном случае является лучшим решением проблем, возникающих у таких народов и стран. В особенности, позволим себе, ещё раз указать на упоминавшееся ранее суждение о том, что правовой плюрализм демонстрирует крайне важную способность решения проблем в переходный период развития государств, что и было доказано рядом групп учёных, проводивших свои исследования на постсоветском пространстве, в частности, в Узбекистане.

При правовом плюрализме, различные системы не только сосуществуют, они начинают взаимодействовать, в результате чего появляются на свет институты ранее не существовавшие и пользу от которых сложно переоценить. В качестве положительного примера реализации концепции правового плюрализма на практике, следует привезти новозеландскую практику реституционного правосудия. Признаем, данный опыт оказался насколько действенным, что вскоре после введения в Новой Зеландии, был перенят рядом развитых государств, находящихся на разных континентах. Более того, был взят на вооружение и Организацией объединённых наций [9, с. 133]. Как авторами ранее упоминалось, «при разрешении конфлликтов с применением реституционного правосудия главный упор делается не на наказание виновного лица и лишение его свободы либо ограждении от общества, а на возмещении ущерба потерпевшей стороне. Поэтому данный, вышедший из обычного права институт и называют восстановительным» [6, с. 155]. К решению проблем, связанных с высоким уровнем преступ- 
ности в среде коренного населения страны - маори, были привлечены обычно-правовые практики самой этой народности. Таким образом, в данном случае можно проследить несомненную пользу правового плюрализма.

Похожая практика существует и в нашей стране. К примеру, в республиках Северного Кавказа имеются и широко применяются примирительные процедуры. Так, народы Дагестана используют исторически сложившийся институт маслаата для разрешения возникших конфликтов [8]. Подобный институт имеется и у вайнахов $[1,5]$

Указанный положительный опыт тесно связан с такой неотъемлемой чертой правового плюрализма как незаменимость при разрешении правовых споров и коноликтов. Как нами отмечалось в более ранних исследованиях по данной тематике, в ряде государств удалось совместить деятельность обычно-правовых судов с судами, которые руководствуются позитивным правом при вынесении решений [6, с. 155].

Согласно Л. Шелефрфу, большая польза правового плюрализма не ограничивается только обеспечением потребностей общества, но и выходит далеко за данные рамки. В частности, предлагает возможные решения для запутанных проблем политического характера, а также для толкования существующих правовых конструкций. В различных аспектах, к примеру, сама сущность федеративных государств требует пересечения правовых систем, в то время как будущее развитие в международном и региональном праве зависит от желания признания параллельных юрисдикций с распределением властных полномочий, где наднациональный суд будет иметь более высокое положение по отношению к национальному. Приведённые примеры демонстрируют проявления правового плюрализма, даже если данная концепция редко используется для описания таких изменений. Однако их важность состоит в их доказательстве жизнеспособности сосуществования конкурирующих правовых систем [19, р. 432]

Однако не только положительные стороны выделяются у правового плюрализма. Некоторыми учёными данная теория нещадно критикуется Так, Балацким Е. В. именно правовому плюрализму вменяются в вину экономические проблемы Автор отмечает, что хозяйствующие субъекты оказываются в условиях, когда конкурирующие нормы, представляющие разные правовые системы, приводят к путанице, так как правовые нормы подвергаются сомнению, но их не отменяют и не изменяют [4].

Согласно Таманахе, правовой плюрализм примечателен совершенно не тем, что сосуществуют многочисленные несогласованные, частично схожие правовые акты, которые регулируют определённые сферы жизнедеятельности, но тем, что они серьёзным образом отличаются. Данный факт приводит к тому, что возникает вопрос о приоритете тех или иных правовых норм, что, в конечном счёте, может повлечь наступление потенциальных конфрликтов между отдельными лицами или в обществе в целом [20, р. 375].

Подобная неуверенность в применимости правовых норм, в особенности, в сложных ситуациях экономического и политического характера, может создать возможность для отдельных категорий лиц или групп общества использовать право для достижения своих собственных целей.

В свою очередь, сложившая негативная ситуация непременно создаст затруднения для государственных органов, которые теряют монопольный характер на осуществление власти. Фактически, наличие правового плюрализма ставит вопрос об авторитете санкционированных государством правовых норм.

Проведённое нами исследование в очередной раз подводит нас к выводу о том, что проблематика правового плюрализма требует дальнейшего изучения. Данное суждение касается как теоретической работы, в частности, над определением понятия правового плюрализма, так и подробного изучения положительного и отрицательного опыта реализации правового плюрализма в современном мире, подверженном влиянию глобализационных процессов. Как было нами продемонстрировано в данной статье, потребность в плюралистическом подходе существует в современных государствах, особенно это касается государств, находящихся на перепутье. Позицию о необходимости отойти от однобокого рассмотрения многих явлений правовой действительности считаем доказанной, при этом также требующей дальнейших исследований

\section{Литература}

1. Албогачиева М. Примирительные комиссии в Ингушетии: история и современность // Традиционные практики урегулирования конфликтов. Материалы ежегодного семинара 2010-2014 гг. (сборник). М.: Общественный центр «Судебно-правовая реформа», 2014. С. 94-117.

2. Антонов М. В. Ойген Эрлих: живое право против правового плюрализма? // Известия высших учебных заведений. Правоведение. 2013. №1. С. 157-181.

3. Бабич И. Л. Формирование правового плюрализма в советское и постсоветское время на Северо-Западном Кавказе // Юридическая антропология. Закон и жизнь. М.: Стратегия, 2000. С. 116-127.

4. Балацкий Е. В. Теория институциональных ловушек и правовой плюрализм // Общеество и экономика. №10. 2001 C. 84-97.

5. Берсанова 3. Обычай кровной мести и практика примирения в современной Чечне // Традиционные практики урегулирования конфликтов. Материалы ежегодного семинара 2010-2014 гг. (сборник). М.: Общественный центр «Судебно-правовая реформа», 2014. С. 118-126.

6. Габрилян Р. Р. К вопросу об обычно-правовых способах разрешения споров и конфликтов (на примере Южно-Тихоокеанского региона) // Гуманитарные и юридические исследования. 2018. №4. С.152-157. 
7. Ковлер А. И. Антропология права и правовой плюрализм (права человека и права народов) // Олень всегда прав. Исследования по юридической антропологии. М.: Стратегия, 2003. С. 24-50.

8. Магомедсалихов X. Г. Маслаат. Традиционные формы разрешения конфликтов у аварцев в XIX - начале XX в Махачкала: Издательский дом «Эпоха», 2003. 174 с.

9. Основные принципы применения программ реституционного правосудия в вопросах уголовного правосудия // Сборник стандартов и норм Организации Объединенных Наций в области предупреждения преступности и уголовного правосудия. Нью-Йорк: ООН, 2007. С. 106-111.

10. Рулан Н. Юридическая антропология. М.: Норма, 2000. 310 c.

11. Тихонова С. В. История правовых норм: правовой плюрализм и коммуникативные теории права // Дискурсы этики. №2(7) 2014. С. 81-98.

12. Antonov M. Global legal pluralism: A new way of legal thinking // Higher School of Economics Research Paper No. WP BPR. 2013. Vol. 10. P. 1-17.

13. Bianchi A. International Law Theories: An Inquiry into Different Ways of Thinking. Oxford: Oxford University Press 2016. XIV+336 p.

14. Dupret B. Legal pluralism, plurality of laws, and legal practices: Theories, critiques, and praxiological re-specification // Eur. J. Legal Stud. 2007. Vol. 1. P. 296-321.

15. Griffiths J. What is Legal Pluralism? // Journal of Legal Pluralism. 1986. No. 24. P. 1-55.

16. Merry S.E. Legal pluralism // Law \& Soc'y Rev. 1988. Vol. 22. P. 869-896.

17. Nader L. The Life of the Law. Berkeley, Los Angeles, London: University of California Press, 2002. 275 p.

18. Petersen H. and Zahle H., Legal Polycentricity: Consequences of pluralism in law. Aldershot: Darmouth, 1995. $245 \mathrm{p}$.

19. Sheleff L.S. The Future of Tradition: Customary Law, Common Law and Legal Pluralism. London: Frank Cass, 1999 $521 \mathrm{p}$.

20. Tamanaha B. Z. Understanding legal pluralism: past to present, local to global // Sydney L. Rev. 2008. Vol. 30. P. 375411.

21. Teubner G. The two faces of Janus: rethinking legal pluralism // Cardozo L. Rev. 1991. Vol. 13. P. 1443-1462.

22. Urinboyev R. and Svensson M. Living law, legal pluralism, and corruption in post-Soviet Uzbekistan // The Journal of Legal Pluralism and Unofficial Law. 2013. 45:3. P. 372-390.

23. Vanderlinden J., Gilissen J. Le pluralisme juridique: essai de synthẻse // Le pluralisme juridique. 1972. P. 19-56

24. von Benda-Beckmann F. Who's Afraid of Legal Pluralism? // The Journal of Legal Pluralism and Unofficial Law. 2002. P.34-82.

\section{References}

1. Albogachieva M. Primiritel'nye komissii v Ingushetii: istoriya i sovremennost' (Reconciliation commissions in Ingushetia: history and modernity) // Tradicionnye praktiki uregulirovaniya konfliktov. Materialy ezhegodnogo seminara 2010-2014 gg (sbornik). Moscow: Social centre «Sudebno-pravovaya reforma» publ., 2014. P. 94-117. (In Russian)

2. Antonov M. V. Ojgen Erlih: zhivoe pravo protiv pravovogo plyuralizma? (Eugen Enlich: Living Law Against Legal Pluralism?) // Izvestiya vysshih uchebnyh zavedenij. Pravovedenie. 2013. No.1. P. 157-181. (In Russian)

3. Babich I. L. Formirovanie pravovogo plyuralizma v sovetskoe i postsovetskoe vremya na Severo-Zapadnom Kavkaze (The formation of legal pluralism in Soviet and post-Soviet times in the North-West Caucasus) // Yuridicheskaya antropologiya Zakon i zhizn'. Moscow: Strategiya publ., 2000. P. 116-127. (In Russian)

4. Balackij E. V. Teoriya institucional'nyh lovushek i pravovoj plyuralizm (Theory of institutional traps and legal pluralism) // Obshchestvo i ekonomika. No. 10. 2001. P. 84-97. (In Russian)

5. Bersanova Z. Obychaj krovnoj mesti i praktika primireniya $v$ sovremennoj Chechne (The blood feud custom and reconciliation practice in modern Chechnya) // Tradicionnye praktiki uregulirovaniya konfliktov. Materialy ezhegodnogo seminara 2010 - 2014 gg. (sbornik). Moscow: Social centre «Sudebno-pravovaya reforma» publ., 2014. P. 118-126. (In Russian)

6. Gabrilyan R. R. K voprosu ob obychno-pravovyh sposobah razresheniya sporov i konfliktov (na primere YuzhnoTihookeanskogo regiona) (On customary legal methods for resolving disputes and conflicts (case study of the South Pacific region) // Gumanitarnye i yuridicheskie issledovaniya. 2018. No. 4. P. 152-157. (In Russian)

7. Kovler A. I. Antropologiya prava i pravovoj plyuralizm (prava cheloveka i prava narodov) (Anthropology of law and legal pluralism (human rights and the rights of peoples) // Olen' vsegda prav. Issledovaniya po yuridicheskoj antropologii. Moscow. Strategiya publ., 2003. P. 24-50. (In Russian)

8. Magomedsalihov H. G. Maslaat. Tradicionnye formy razresheniya konfliktov $u$ avarcev $v$ XIX - nachale XX v. (Maslaat. Traditional forms of conflict resolution among Avars in the 19th - early 20th centuries). Mahachkala: Publishing House «Epokha», 2003. 174 p. (In Russian)

9. Osnovnye principy primeneniya programm restitucionnogo pravosudiya $v$ voprosah ugolovnogo pravosudiya (Basic principles on the use of restorative justice programmes in criminal matters) // Sbornik standartov i norm Organizacii Ob'edinennyh Nacij v oblasti preduprezhdeniya prestupnosti i ugolovnogo pravosudiya. NY: UN publ., 2007. P. 106-111. (In Russian)

10. Rouland, N. Yuridicheskaya antropologiya (Legal Anthropology). M.: Norma, 2000. 310 p. (In Russian)

11. Tihonova S. V. Istoriya pravovyh norm: pravovoj plyuralizm i kommunikativnye teorii prava (History of legal norms: legal pluralism and communicative theory of law) // Al'manah "Diskursy etiki». No.2(7) 2014. P. 81-98. (In Russian)

12. Antonov M. Global legal pluralism: A new way of legal thinking // Higher School of Economics Research Paper No. WP BPR. 2013. Vol. 10. P. 1-17.

13. Bianchi A. International Law Theories: An Inquiry into Different Ways of Thinking. Oxford: Oxford University Press, 2016. XIV+336 p. 
14. Dupret B. Legal pluralism, plurality of laws, and legal practices: Theories, critiques, and praxiological re-specification // Eur. J. Legal Stud. 2007. Vol. 1. P. 296-321.

15. Griffiths J. What is Legal Pluralism? // Journal of Legal Pluralism. 1986. No. 24. P. 1-55.

16. Merry S.E. Legal pluralism // Law \& Soc'y Rev. 1988. Vol. 22. P. 869-896.

17. Nader L. The Life of the Law. Berkeley, Los Angeles, London: University of California Press, 2002. 275 p.

18. Petersen H. and Zahle H., Legal Polycentricity: Consequences of pluralism in law. Aldershot: Darmouth, 1995. 245 p.

19. Sheleff L. S. The Future of Tradition: Customary Law, Common Law and Legal Pluralism. London: Frank Cass, 1999. $521 \mathrm{p}$.

20. Tamanaha B. Z. Understanding legal pluralism: past to present, local to global// Sydney L. Rev. 2008. Vol. 30. P. 375411.

21. Teubner G. The two faces of Janus: rethinking legal pluralism // Cardozo L. Rev. 1991. Vol. 13. P. 1443-1462

22. Urinboyev R. and Svensson M. Living law, legal pluralism, and corruption in post-Soviet Uzbekistan // The Journal of Legal Pluralism and Unofficial Law. 2013. 45:3. P. 372-390.

23. Vanderlinden J., Gilissen J. Le pluralisme juridique: essai de synthèse // Le pluralisme juridique. 1972. P. 19-56

24. von Benda-Beckmann F. Who's Afraid of Legal Pluralism? // The Journal of Legal Pluralism and Unofficial Law. 2002. P. 34-82.

\section{Сведения об авторах}

Габрилян Роман Русланович - кандидат юридических наук, доцент кафедры теории и истории государства и права юридического института Северо-Кавказского федерального университета (Ставрополь) / roman@gabrilyan.com

Клюковская Ирина Николаевна - доктор юридических наук, профессор, заведующая кафедрой теории и истории государства и права юридического института Северо-Кавказского федерального университета (Ставрополь) / klyukovskaya@inbox.ru

Конина Елена Николаевна - кандидат юридических наук, доцент кафедры теории государства и права Ставропольской государственной юридической академии (Саратов) / elenapalagina4@rambler.ru

\section{Information about the authors}

Gabrilyan Roman - PhD in Law, Associate Professor, Chair of Theory and History of State and Law, Institute of Law, North-Caucasus Federal University (Stavropol) / roman@gabrilyan.com

Klyukovskaya Irina - Doctor of Legal Science, Professor, Head of Chair of theory and history of State and Law, Institute of Law, North-Caucasus Federal University (Stavropol) / klyukovskaya@inbox.ru

Konina Elena - PhD in Law, Associate Professor, Chair of Theory of State and Law, Saratov State Academy of Law (Saratov) / elenapalagina4@rambler.ru 